\title{
Las artes y la cultura en la encrucijada de la hiper-virtualidad
}

Recibido: 29 de abril 2021

Revisado: 4 de mayo 2021 Aprobado:25 de mayo 2021

Nilson Oviedo Valerio Costarricense. Bachiller en sociología y bajista de las bandas

Endemia, La Milixia y Los Garbanzos. Investigador, ejecutor de proyectos y gestor cultural de la Cooperativa Sulá Batsú R.L. (Costa

Correo electrónico: nilson@sulabatsu.com

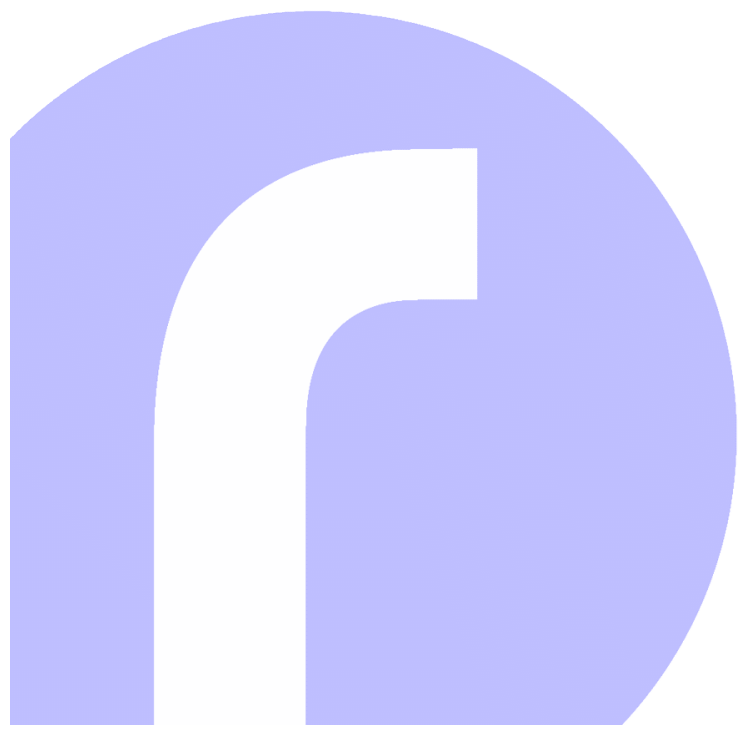

https://revistas.uned.ac.cr/index.php/rupturas (c) (1) (2)
Resumen: En el presente texto conversamos y debatimos sobre el papel las Tecnologías Digitales en la pandemia global actual con respecto a las artes y la cultura, cómo el fenómeno de la hiper-virtualización ha pasado a ser la forma principal de producir y consumir expresiones artísticas y culturales, así como sus principales aspectos y tensiones, tanto desde las personas creadoras de estas expresiones, así como desde el consumo por parte del público.

Palabras clave: arte y cultura, tecnologías digitales, hiper-virtualización, consumo, internet

\section{Arts and Culture at the Crossroads of hyper-virtuality}

Abstract: In this text we talk and debate about the role of Digital Technologies in the present global situation. How the phenomenon of hypervirtualization has become the main way of producing and consuming artistic and cultural expressions. As well as its main aspects and tensions, both from the creators of these expressions, as well as from the consumption by the public.

Key words: Arts and culture, Digital Technologies, Hyper-virtualization, consumption, Internet 


\section{Las artes y la cultura en la encrucijada de la hiper-virtualidad}

El mes de Marzo del 2020 marcó el inicio de la historia de la pandemia en Costa Rica, ya que fue el mes donde se reportó oficialmente el primer caso de COVID-19 en el país, y tan solo unos días después, se aplicaron cierres y prohibiciones de diversa índole con el fin de detener el avance de la misma. Las presentaciones artísticas y culturales, incluyendo la exponencialmente creciente industria del espectáculo, entendida en su más amplia y variada concepción, se vieron totalmente detenidas por supuesto, situación que vino a deteriorar la ya de por sí muy deteriorada condición de las personas trabajadoras del arte y la cultura del país propiamente (UNESCO 2020a).

Las obras de teatro, las salas de conciertos y exposiciones, los espacios al aire libre, y por supuesto los eventos musicales, tanto masivos como los de menor escala, fueron inmediatamente cancelados. El amplio sector cultural, no solo las personas que se dedican a las artes propiamente, sino también todo el personal técnico y de gestión cultural, fueron afectadas de inmediato por todas estas medidas de salud adoptadas por los Estados en todo el mundo, medidas adecuadas y sin duda necesarias para paliar el avance del virus, pero que a nivel socioeconómico, y en el marco de un sistema económico vorazmente capitalista, individualista además, ha significado un empobrecimiento generalizado de diversos sectores sociales en todo el mundo (Banco Mundial 2020).

Dichas medidas de distanciamiento y prohibición de eventos, naturalmente han resultado antagónicas a la propia lógica del desarrollo de las artes y la cultura, que son intrínsecamente físicas, es decir, la experiencia de la vivencia física de las expresiones artísticas les dota de su esencia, es ahí donde emana su riqueza cultural propiamente, en el territorio de lo físico. El arte y la cultura en general se desarrollan y se magnifican en lo físico, es en el campo, en la presencialidad de las expresiones artísticas, donde se alcanza su verdadero poder simbólico (Pinto y Pereyra 2011).

Este escenario de cancelaciones en el plano presencial lanzó al mundo de las artes y la cultura a las presentaciones en línea dentro de la era digital, un fenómeno que ya se venía dando paulatina e incesantemente desde diversas plataformas digitales como Youtube o Facebook, entre otras. El 2020 no hizo más que amplificar este fenómeno que hemos llamado en el presente artículo de la hiper-virtualidad de las artes y la cultura; fenómeno que no solo ha funcionado como una especie de respirador artificial a una realidad nunca antes conocida por nuestras generaciones de artistas ante la ausencia de eventos presenciales, sino que ha venido a establecer nuevos cuestionamientos al qué hacer de muchas de las expresiones artísticas actuales (Carballo 2020). 
Definimos hiper-virtualidad a esa instancia en la que las tecnologías digitales nos brindan la facilidad ya no solo de hacer llamadas o enviar mensajes de texto, sino de realizar compras, escuchar música, ver videos, realizar reuniones, y más en la línea del presente texto, realizar tours a museos, comprar "entradas" para shows en línea, shows de teatro, de danza, de música, de comedia, y un sin fin de posibilidades.

Con la pandemia, un tsunami de toda clase de eventos virtuales se nos vino encima, desde conciertos inéditos "subidos" a las redes y canales oficiales de artistas, obras de teatro y danza de diversas compañías de todo el mundo transmitidas en vivo y en directo desde los escenarios más reconocidos, pasando por ejercicios de yoga o clases de baile en casa, y una gran variedad de eventos más que intentaban hacer la cuarentena más llevadera (UNESCO 2020b).

¿Pero qué significa esto para las artes y la cultura del espectáculo y el entretenimiento propiamente? ¿Cuál es el impacto mediato e inmediato en las personas trabajadoras del arte y la cultura? El abordaje para responder a estas preguntas desde el presente artículo gira en torno a una dualidad, por un lado, desde la persona creadora y, por el otro, desde la persona consumidora de arte, y su uso y acceso al internet, así como las herramientas y plataformas digitales que le permiten consumir todo tipo de entretenimiento en línea.

\section{Hablemos de las personas creadoras.}

Como ya lo mencionamos, la pandemia no solo trajo la total inactividad presencial de su qué hacer, con las consecuentes problemáticas de satisfacción de necesidades básicas inmediatas, sino que vino a acrecentar las desigualdades estructurales de la industria cultural, ya que muchas y muchos artistas consolidados de la industria más enfocada en el espectáculo masivo, y con un poder y una capacidad económica gigantesca, lograron producir eventos de muy alta calidad, tanto en equipo como en transmisión, además de contar con apoyos de patrocinadores que les permitieron satisfacer cualquier necesidad que se les presentara.

Por un lado, Metallica empezó a publicar conciertos inéditos que denotaban su capacidad de documentar shows; mientras tanto, Fito Páez nos deslumbraba con su piano de cola desde la sala de su apartamento. El Louvre habilitó tours virtuales para mirar sus obras únicas; Broadway puso a disposición sus espectáculos en línea; entre muchas otras presentaciones magníficas que desbordaron nuestra capacidad de mirar una pantalla por tanto tiempo.

Mientras tanto, la gran mayoría de personas trabajadoras del arte se vieron totalmente abandonadas a su suerte, ya que la autogestión de los proyectos artísticos es el principal modelo de organización que se encuentra en el sector; en este modelo se suele asumir todo el proceso de creación y de difusión, así como las diversas tareas que se presentan. Por lo tanto, bajo este 
modelo, las personas artistas se vieron en la necesidad de aprender sobre la marcha sobre las nuevas y no tan nuevas herramientas digitales, donde las realizaciones caseras eran la constante, con calidades tan variadas y disímiles, tanto de sonido, como visuales, producto del acceso desigual a las tecnologías de grabación de audio y video, y con el gran océano de publicidades difuminadas en las diversas plataformas de la red.

Las asimetrías de la industria artística se reprodujeron y se amplificaron en esta virtualidad, el impacto de eventos de grandes artistas era sin duda mucho más mediático que el artista local que buscaba mantenerse y generar recursos. Así como la conectividad, que también juega un papel preponderante en el consumo, pero que desde este lado de la virtualidad también marcó grandes y marcadas diferencias, sobre todo en la calidad de las transmisiones.

\section{¿Y qué pasa del otro lado de la pantalla?}

Por otro lado, el consumo de arte también se vio trastocado por este fenómeno de la hiper-virtualidad que produjo el COVID-19; el bombardeo masivo de eventos virtuales ha sido la tónica en los meses siguientes a marzo del 2020, donde las personas espectadoras han visto sus redes cargadas de eventos de sus artistas internacionales favoritas y favoritos y un sinnúmero de eventos de artistas locales que buscan de diversas formas seguir con su actividad artística.

Las personas consumidoras de arte en tiempos de pandemia también se ven afectadas por la accesibilidad al internet, ya que muchas transmisiones de las y los artistas llamados "mainstream" son elaboradas con una calidad de internet mucho más alta de la que se suele contar en nuestros países de América Latina, por lo que es común que las transmisiones tengan retrasos o saltos, o incluso cortes de transmisión. Es así como la brecha digital no solo se marca entre artistas, sino también entre espectadores, donde solo en América Latina hay 77 millones de personas sin acceso a internet de calidad, principalmente en zonas rurales (CEPAL 2020).

En cuanto al fenómeno del streaming, definido como el consumo de contenido en línea sin la necesidad de descargarlo, también refleja asimetrías en cuanto a lo que culturalmente se consume, ya que el público es mucho más susceptible a consumir lo que las mismas redes sociales nos sugieren, por el desarrollo de estrategias de marketing digital asociadas a los equipos de trabajo con que cuentan las y los artistas de renombre.

\section{Otros aspectos a tomar en cuenta}

Este es un panorama de desigualdades estructurales en torno a las artes y la cultura, tanto desde las personas creadoras como desde el público que con- 
sume las creaciones, principalmente performativas, sin embargo, el resto de expresiones culturales que cuentan con un carácter mucho más enraizado en lo físico, como las artes plásticas, quedan aún más rezagadas en esta hipervirtualidad pandémica, ya que las herramientas para llevar sus expresiones artísticas al mundo de las redes digitales están mucho más vinculadas a lo visual, pero sobre todo táctil, sentido que la virtualidad aún no ha colonizado.

Por otra parte, las personas trabajadoras del arte, con contadas excepciones, siguen siendo la parte más débil y con mayores problemas en lo que respecta a la implementación y ejecución de herramientas digitales con fines de difusión, siendo el streaming la forma más utilizada para consumir y utilizar contenido artístico, a su vez que las plataformas reproducen asimetrías en el pago por el uso de estos contenidos artísticos, asimetrías que se reflejan y se reproducen en toda la cadena del sector cultura.

A manera de conclusión, es de suma importancia entender esta situación a profundidad, donde la gran mayoría de artistas de todas las disciplinas no reciben remuneraciones por el uso y explotación de sus obras en internet, o bien, las remuneraciones suelen ser de centésimas de dólar, mientras que las plataformas generan ingresos millonarios que aumentan año con año; y por otro lado, el consumo de producciones artísticas "transnacionales" acrecienta la brecha entre estos y las producciones locales.

Para transformar este círculo vicioso en un círculo virtuoso, es urgente atender estas y otras emergencias culturales, tanto del Estado en sus diversas instancias, principalmente (pero no las únicas) el Ministerio de Cultura y Juventud así como las diversas Oficinas de Cultura de las Municipalidades, donde no hay una comprensión global e integral del qué hacer artístico, limitando su accionar a visiones marcadamente institucionalizadas.

Además, una regulación y el reconocimiento de una remuneración justa del sector artístico, así como el fomento de expresiones locales pasa por la generación de políticas públicas que regulen las tecnologías digitales e incentiven la producción artística y local, en un marco de respeto de los Derechos Humanos en materia de Cultura, tomando como referencia la Recomendación relativa a la condición del artista, publicada por la UNESCO en 1980, la cual menciona una serie de recomendaciones que buscan el mejoramiento de las condiciones materiales de las personas trabajadoras del arte y la cultura, y que su octavo principio rector establece que:

Los Estados Miembros deberían procurar que toda perso-

na, sin distinción de raza, color, sexo, idioma, religión, opinión política o de otra índole, origen nacional o social, y condición económica o linaje, tenga la misma posibilidad de adquirir y desarrollar la formación necesaria para lograr su plena realización y el ejercicio de sus 


\section{facultades artísticas y para obtener un empleo y ejer- cer su profesión sin discriminación (UNESCO 1980).}

\section{Bibliografía:}

Carballo Villagra, Priscilla. 2020. "Voz experta: El COVID-19 y el sector cultura: aplaudir no alcanza". UCR. Acceso el 20 de abril, 2021.

https://www.ucr.ac.cr/noticias/2020/07/21/voz-experta-el-covid-19-y-el-sectorcultura-aplaudir-no-alcanza.html

Banco Mundial. 2020. "La COVID-19 (coronavirus) hunde a la economía mundial en la peor recesión desde la Segunda Guerra Mundial”. Acceso el 20 de abril, 2021. https://www.bancomundial.org/es/news/pressrelease/2020/06/08/covid-19-to-plunge-global-economy-into-worstrecession-since-world-war-ii

Heidegger, Martín. 2009. El arte y el espacio. Editado y traducido por Jesús Adrián Escudero. España: Herder Editorial.

IICA. 2020. "Al menos 77 millones de personas, sin acceso a internet de calidad en áreas rurales de América Latina y el Caribe". Acceso el 20 de abril, 2021. https://www.iica.int/es/prensa/noticias/al-menos-77millones-de-personas-sin-acceso-internet-de-calidad-en-areas-rurales$\underline{\text { de }}$

Pinto, Silvia y Alicia Pereyra. 2011. "Hacia una mirada científica en torno del arte como proceso y producto social". Revista Iberoamericana de Educación 55(2): 1-10. Universidad Nacional de la Patagonia Austral, Argentina.

UNESCO. 1980. "Recomendación relativa a la condición del artista". Acceso el 23 de abril, 2021. http://portal.unesco.org/es/ev.phpURL_ID=13138\&URL_DO=DO_TOPIC\&URL_SECTION=201.html

UNESCO. 2020a. “¿Cómo la crisis de la COVID-19 afecta al sector cultura en América Central”. Acceso el 19 de abril, 2021.

https://es.unesco.org/news/como-crisis-covid-19-afecta-al-sector-culturaamerica-central

UNESCO. 2020b. "En época de COVID-19 el mundo consume arte y cultura". Acceso el 19 de abril, 2021. https://es.unesco.org/news/epoca-covid19-mundo-consume-arte-y-cultura 